\title{
Corrosion behavior and resistance parameters of silicon carbide nanocomposite coating on different metals
}

\author{
M.J. Suriani ${ }^{1 *}$, W.B.W. Nik ${ }^{1}$, F. Mansor ${ }^{1}$,M.N.K. Jarkoni ${ }^{1}$, C.W. Maizurah ${ }^{1}$ and $^{\text {I. }}$ \\ Izwani $^{1}$
}

School of Ocean Engineering, Universiti Malaysia Terengganu (UMT), 21030 Kuala

Nerus, Terengganu, Malaysia

Phone: +6096683716; Fax: +6096683991

*Email: surianimatjusoh@umt.edu.my

\begin{abstract}
Silicon carbide (SiC) films were deposited on stainless steel (SS), mild steel (MS) and aluminium ( $\mathrm{Al}$ ) from a $\mathrm{SiC}$ targeted in a magnetron sputtering system to produce the amorphous SiC coating. Magnetron sputtering is a Physical Vapor Deposition process for deposited material onto substrate by ejecting atom from such $\mathrm{SiC}$ and condensing the ejected atom onto SS, MS and Al metals in high vacuum environment. The behavior of the films as corrosion protection barriers in different concentrations of sodium chloride $(\mathrm{NaCl})$ solution in $0.5 \mathrm{M}$ and $1.0 \mathrm{M}$ at different temperatures $\left(30^{\circ} \mathrm{C}\right.$ and $\left.50^{\circ} \mathrm{C}\right)$ were evaluated by electrochemical impedance spectroscopy (EIS) measurements. Films on SS exhibited a better corrosion resistance than MS and Al. The weight loss measurement, it shows that uncoated metals loss more weight than coated metals for longer time of immersion. Meanwhile the EIS results also depicted that the polarization resistance, $\left(\mathrm{R}_{\mathrm{p})}\right.$ coated metals indicates higher value compared to uncoated metals. The water salinity and temperatures also showed a significant effect on polarization resistance, $\left(R_{p}\right)$ for both coated and uncoated metals. The $R_{p}$ are decreased with the increased of salinity and temperature accordingly. X-ray diffraction (XRD) used for determination of phase identification. Based on XRD, there are no higher peaks were obtained on $\mathrm{SiC}$, and showed that $\mathrm{SiC}$ were confirmed amorphous. It concluded that this study shows corrosion rate of coated metals was decreased obviously compared to uncoated metals and $\mathrm{SiC}$ nanocomposite coating performed a significant corrosion behaviors and resistance parameter on different metals.
\end{abstract}

Keywords: Silicon carbide, magnetron sputtering, nanocomposite coating, corrosion.

\section{INTRODUCTION}

Corrosion is an aqueous environment and in an atmospheric environment and in an atmospheric environment which also involves thin aqueous layers is an electrochemical process because corrosion involves the transfer of electrons between a metal surfaces and an aqueous solution. It results from overwhelming tendency of metals to react electrochemically with oxygen, water, and other substances in the aqueous environment [1]. Usually, corrosion occurs because of reactivity of metals, presence of air, moisture, gases like $\mathrm{SO}_{2}$ and $\mathrm{CO}_{2}$ and presence of electrolyte. Therefore, coating a metal surface with paint or enamels provides barriers between the metal and the moisture in the environment [2-4]. In addition, removing the opportunity for both oxygen and moisture to come in contact with the metal is some of example to prevent corrosion [5-7]. 
Coatings of $\mathrm{SiC}$ excessively used for low friction and high wear resistance applications [8]. The applications had expanded in various scope including aerospace, blacksmith, coatings protection in steel, coatings protection against high temperature gas-cooled reactors, against high temperature and biological attacks [9-13]. The methods by dynamic ion mixing, RF magnetron sputtering, and chemical deposition are costly, unsuitable for large-scale components and size limitation [9-11, 14, 15]. Since many years, groups of researchers studied $\mathrm{SiC}$ film as main interest because of their combination of inimitable physiochemical, electrical and mechanical properties [16-17]. The main purpose of applying $\mathrm{SiC}$ coating technology as protective layer to the surface coated is to increase the lifetime or the performance when it is visible to aggressive environments. The very strong covalent bond between silicon and carbon and its tetrahedral synchronization is the satisfactory explanation to achieve the main purpose [18-20]. However, solid adhesion to the substrate and low density of holes and cracks must be obeyed to achieve excellent protective layer. Studies on SiC coating films for it characterization for better result of structure and adhesion, wide range of methods for $\mathrm{SiC}$ film deposition and deposition limitations had been done [21-23]. Besides, mixture of organic polymers for its elasticity and water resistance with inorganic materials for its hardness and permeability stimulates the effectiveness and efficiency of nanocomposite of polymer coating. Nanocomposite had arisen as suitable alternatives to overwhelmed limitation of microcomposite and monolithics while posturing research challenges related to the controlled component of composition and stoichiometry in the nanocluster field [24-25].

Sputtering is a momentum transfer process. When a particle strikes a surface the process that follows impact depend on the energy of the incident particle, the angle of incidence, the binding energy of surface atoms and the mass of the colliding particles. The "racetrack" form by confining electric field strength and magnetic flux increasing the number of ionization of electron as magnetron cathode is elementary for magnetically enhanced diode. Factors for excellent result are power density on the targeted metals, erosion area, distance of substrate, target material, sputter yield and gas pressure [26-28]. The salinity of open ocean water at the surface typically varies from 32 to 37.5 parts per thousand. In more isolated seas where there are large variations in salinity, these large variations can affect a metal's uniform corrosion rate. Seawater is much more dilute than open seawater at river mouth, under saturated carbonates which dropping forming protective calcareous films on metal surface [29-30]. The temperature influences the corrosion rate by factor of its effect on the oxygen solubility and oxygen diffusion coefficient. As the temperature increase, the oxygen diffusion coefficient also increases which leads to increasing in corrosion rate. Besides that, the influence of temperature toward the corrosion rate increase because of it tend to change the nature of corrosion film which more granular and non-adherent in high temperature [31-32]. Increasing the value of temperature causes the increase in the amount of corrosion rate [33]. This is referring to the increasing of activation energy for chemical and electrochemical reactions, increased diffusion rates in the electrolyte and increase transport of the current through the electrolyte. The passive film is tending to break down repetitively over a fairly narrow temperature range. To summarize it, the corrosion rate for heated element is higher than unheated elements and it will increase during summer compared to winter [36]. This study might contribute the best solution for corrosion of metal by applying the silicon carbide nanocomposite coating as a protective film. Silicon carbide nanocomposite coating offer highly protection corrosion resistance between the surface of metal and the environment. This work was carried out 
in order to use the electrochemical impedance spectroscopy (EIS) for the investigation of the corrosion resistance of amorphous $\mathrm{SiC}$ coatings produced by magnetron sputtering at different deposition conditions on steel and silicon substrates.

\section{EXPERIMENTAL SET UP}

\section{Design of Experiment}

Samples of MS, SS and Al were cleaned by using polishing machine and cutting machine. Polishing process is one of the surface cleaning processes usually used for metal before coating process will be conducted. The metals were polished with 180, 600,1200 and 2000 of emery paper using polishing machine. Firstly, the holder was lowered to the plate. Then, the samples were put on the holder. The machine was being operated by using 60,100, 125 and 180 powers. After 60 seconds, the machine was being stopped and the oxide layers from the metals will be eliminated. Then the metals were being cut using cutter machine.

\section{Experimental Procedure \\ Coating Process by Magnetron Sputtering}

First, metals were polished again with sand paper to remove the oxide layer. Then, ionized water was used to rinse the metals for cleaning surface. Then, metals were immersed with isopropanol in beaker before metals were placed into ultrasonic bath in 10 minutes for remove the contaminant on the metals. After 10 minutes, metals were dried with air blower by using Nitrogen gas before placed in substrate holder. The chamber, shutter and metal holder were cleaned up with isopropanol to remove contaminant on the metals. Then, silicon carbide as sputtering target was located at the holder.

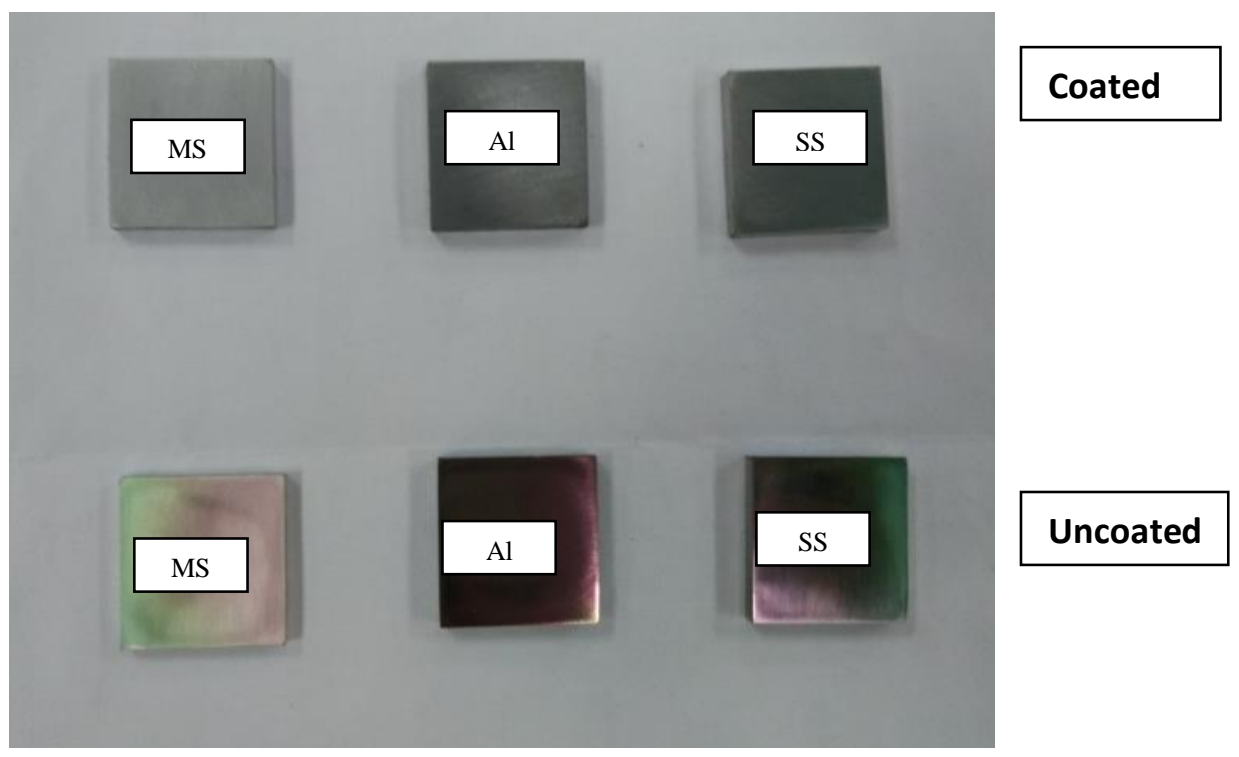

Figure 1. Coated and uncoated test coupon by MS, Al and SS consecutively. 
Shutter also located at the upper of the sputtering target. Meanwhile, metals were attached at the substrate holder. The chamber was closed and Nitrogen gas was supplied for vacuum process. Vacuum process are necessary for avoid the gas mix with oxygen. Then, the chamber was depressurized from $10^{-3}$ to $10^{-5}$ torr to create the plasma in the chamber and the temperature was set up to $200^{\circ} \mathrm{C}$. Argon gas was flow into the chamber to create bombarded ion and RF generator was on. Shutter was open to allow the ion and deposition was started. After 30 minutes, shutter was closed to make sure that no iron movement in the chamber and the deposition was abroad. Finally, substrate was left into the chamber until it cool down to room temperature. Fabrication of Magnetron sputtering process is following ASTM E-112, "Metal test methods and analytical procedures [35]. Figure 1. Depicted coated and uncoated test coupon by MS, Al and SS consecutively.

\section{Characterization}

X-ray diffraction used to determine a wealth of structural, physical and chemical information about the material. When a monochromatic X-ray beam with wavelength lambda is projected onto a crystalline material at an angle theta diffraction occurs only when the distance traveled by the rays reflected from successive planes differs by a complete number $\mathrm{n}$ of wavelengths. By varying the angle theta, the Bragg's Law conditions are satisfied by different d-spacing in polycrystalline materials. Plotting the angular position and intensities of the resultant diffracted peaks of radiation produces a pattern, which is characteristic of the sample. Where a mixture of different phases is present, the resultant diffractogram is formed by addition of the individual patterns. In this research, metals that coated with silicon carbide nanocomposite will be displace into X-ray diffractometer to determine the structural properties of metals such as defect structure and grain size.

\section{Weight Loss Measurement}

Metals coated with silicon carbide nanocomposite were weighted before and after 30 days immersed with seawater and dilute $\mathrm{NaCl}$ solution at $0.5 \mathrm{M}$ and $1.0 \mathrm{M}$ to observe the differential weight loss of these metals. The value of weight loss during the process was calculated using the Eq. (1):

$$
w_{l}=w_{o}-w_{i}
$$

Where:

$w_{l}=$ weight loss, $w_{o}=$ specimen initial weight and $w_{i}=$ specimen final weight

\section{Corrosion Rate}

The corrosion rate in mils per year (mpy) was calculated from the weight loss using the formula in Eq. (2) [34]:

$$
C R=\frac{W}{(D \times A \times t)} \times k
$$

where $W=$ weight loss in gram; $k=$ constant $(22300) ; D=$ metal density $\left(\mathrm{g} / \mathrm{cm}^{3}\right) ; A=$ coupon area $\left(\right.$ inch $\left.^{2}\right) ; t=$ time (days) 


\section{Electrochemical Impedance Spectroscopy}

SS, MS and Al were immersed into different concentration such as seawater and dilute $\mathrm{NaCl}$ solution. The samples were immersed in the $0.5 \mathrm{M}$ and $1.0 \mathrm{M}$ of dilute $\mathrm{NaCl}$ solution. The samples also immersed in natural seawater to distinguish the effect of salinity with different parameters. For the effect of temperature, $30^{\circ} \mathrm{C}$ and $50^{\circ} \mathrm{C}$ were chosen to observe the corrosion resistances of samples coated with silicon carbide nanocomposite. One of the metals was taken out and placed in the electrochemistry cell. The cell consists of working electrode (WE), platinum wire counter (auxiliary) electrode (CE) and standard calomel electrode (SCE) or also known as reference electrode (RE) was arranged in contact with the electrolyte and connected to measurement software. The purpose of using $\mathrm{CE}$ is to allow the current move in the circuit created by the investigation and RE is present to provide a very stable datum point against which the potential of working electrode can be measured. An even and consistent reference electrode was a significant constituent of most electrochemical test methods. In this technique, it is use the general purpose electrochemical system to calculate the resistance parameter and the cell was connected to a computer. For the EIS technique, it used Autolab frequency response analyser (FRA) and it was produced the Nyquist Plot and Bode Plot. It recorded the real (resistive) and imaginary (capacitive) components of the impedance response, $Z$ ' and $-Z$ '', respectively. The electric source which AC potential with some of its amplitude range is apply to the cell and the current through the cell was measured in order to get the impedance. The analysis of the impedance data from both plots was studied to investigate the corrosion resistance of metals.

\section{RESULTS AND DISCUSSION}

\section{Weight Loss Measurement}

When two metals are electrically connected to each other in an electrolyte, electrons flowed from more active metal to other due to the difference in the electrical potential, the so called driving force. When the most active metal supplies current, it gradually dissolved into ions in the electrolyte. And at the same time produce electrons which the lease active will receive through the metallic connection with the anode [37]. The result obtained the variation of weight loss with exposure time, and the corresponding corrosion rate versus exposure time for coated and uncoated metals immersed in seawater for duration of 30 days or 4 weeks. From the Table 1, it can be observed that there were minimal rises in weight loss of metals that coated with silicon carbide but a relatively greater weight loss was achieved for the uncoated metal especially for mild steel. The metal surface that coated with silicon carbide exposed to the seawater for 30 days could be observe that there was a considerable decrease in weight loss of coated metal throughout the experiment. 
Table 1. Variation of weight loss $\left(\mathrm{w}_{\mathrm{l}}\right)$ and Corrosion Rate (CR) on different type of metals upon immersion time.

\begin{tabular}{lccc}
\hline Type of Metal & Days & Weight Loss, $\mathrm{w}_{1}(\mathrm{~g})$ & $\begin{array}{c}\text { Corrosion Rate, CR } \\
(\mathrm{mm} / \text { year })\end{array}$ \\
\hline Uncoated Mild Steel & 7 & 0.0114 & 1.0027 \\
& 14 & 0.0146 & 2.0054 \\
Uncoated Aluminium & 21 & 0.0152 & 3.0081 \\
& 30 & 0.0185 & 4.2973 \\
& 14 & 0.0018 & 0.3557 \\
Uncoated Stainless Steel & 21 & 0.0022 & 0.7114 \\
& 30 & 0.0025 & 1.0671 \\
& 14 & 0.0028 & 1.5244 \\
Coated Mild Steel & 21 & 0.0001 & 0.0071 \\
& 30 & 0.0001 & 0.0141 \\
& 7 & 0.0001 & 0.0212 \\
Coated Aluminium & 14 & 0.0001 & 0.0303 \\
& 21 & 0.0080 & 0.6164 \\
& 30 & 0.0088 & 1.2328 \\
& 7 & 0.0094 & 2.6417 \\
& 14 & 0.0008 & 0.1739 \\
Coated Stainless Steel & 21 & 0.0010 & 0.3478 \\
& 30 & 0.0013 & 0.5217 \\
& 7 & 0.0018 & 0.7453 \\
& 14 & 0.0000 & 0.0000 \\
& 21 & 0.0000 & 0.0000 \\
& 30 & 0.0000 & 0.0000 \\
& & 0.0001 & 0.0016 \\
\hline
\end{tabular}

\section{Corrosion Rate}

For the specimen without inhibitor, the $\mathrm{Cl}$ - ion increased current density at a definite potential indicating the passivity break down and initiation of pitting corrosion. The reducing of passivity was contributed by absorption of chloride ions onto the layer forming at the metals [38-39]. However, by coating silicon carbide nanocomposite coating into the metals, it acts as passive layer which can support the metal surface and reduce ions transfer from the metals. From Table 1, corrosion rate of coated metal was decrease obviously compared to the uncoated metals. The present of inhibitor shows a significant anticorrosion activity on metals by silicon carbide nanocomposite. $\mathrm{SiC}$ is an interesting material to be used as a protective coating to improve the lifetime or the performance of metallic substrates when exposed to aggressive environments [40].

\section{Electrochemical Impedance Spectroscopy}

Through the Nyquist plots metals coated with silicon carbide and uncoated, it showed the impedance diagram which is the single capacitive semicircles. The changes of semicircles indicate charge transfer control the corrosion process. The entire electrochemical tests were performed in different parameters of salinity and 
temperature. The slope of the polarization resistance, $R_{p}$ decrease after immersion time increased. The higher $R_{p}$ value indicates the lower the corrosion rate [41].

\section{Effect on Salinity}

$0.50 \mathrm{M}$ and $1.0 \mathrm{M}$ of $\mathrm{NaCl}$ solution react as electrolyte in the electrochemical test. The EIS data of different types of metals are presented as Nyquist plot, which was comprised of real and imaginary parts of the impedance as a function of the applied frequency perturbation. A convenient way to evaluate the corrosion properties of the samples is to compare the diameter is, the better corrosion resistance of the samples were gained [42]. The metals that coated with silicon carbide nanocomposite exhibited larger diameters than the metals with uncoated and the better corrosion resistance of these coated metal were evident as shown in Figure 2. (i), (ii) and (iii) respectively.

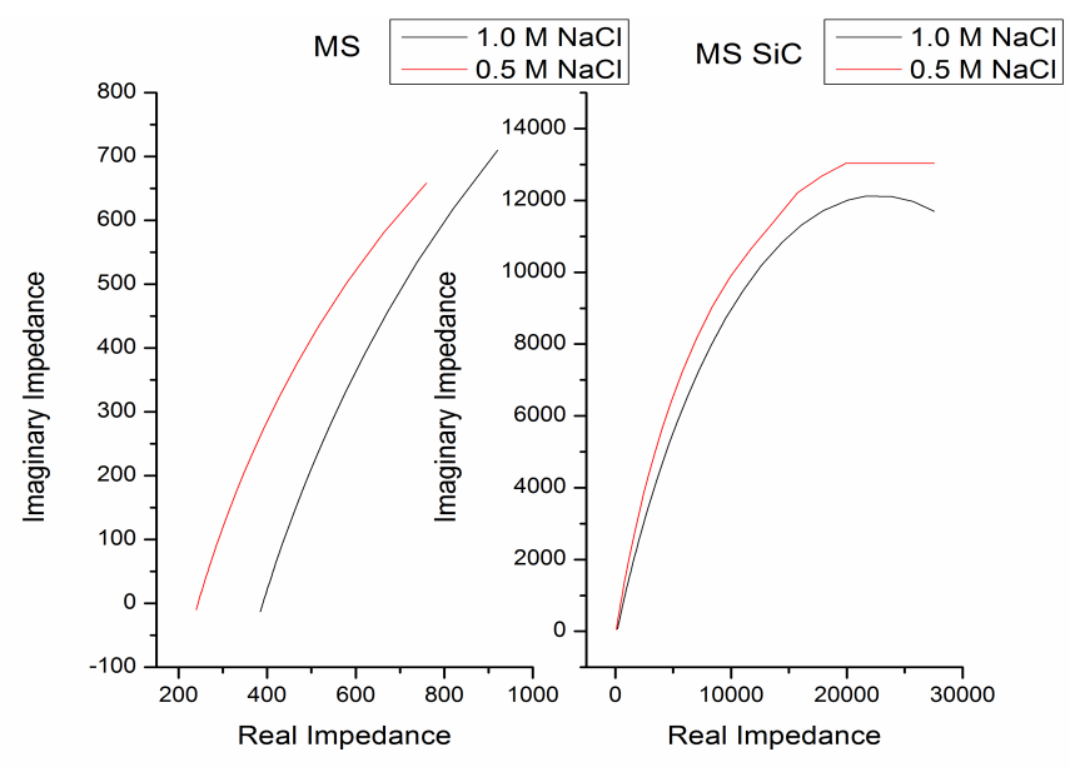

MS

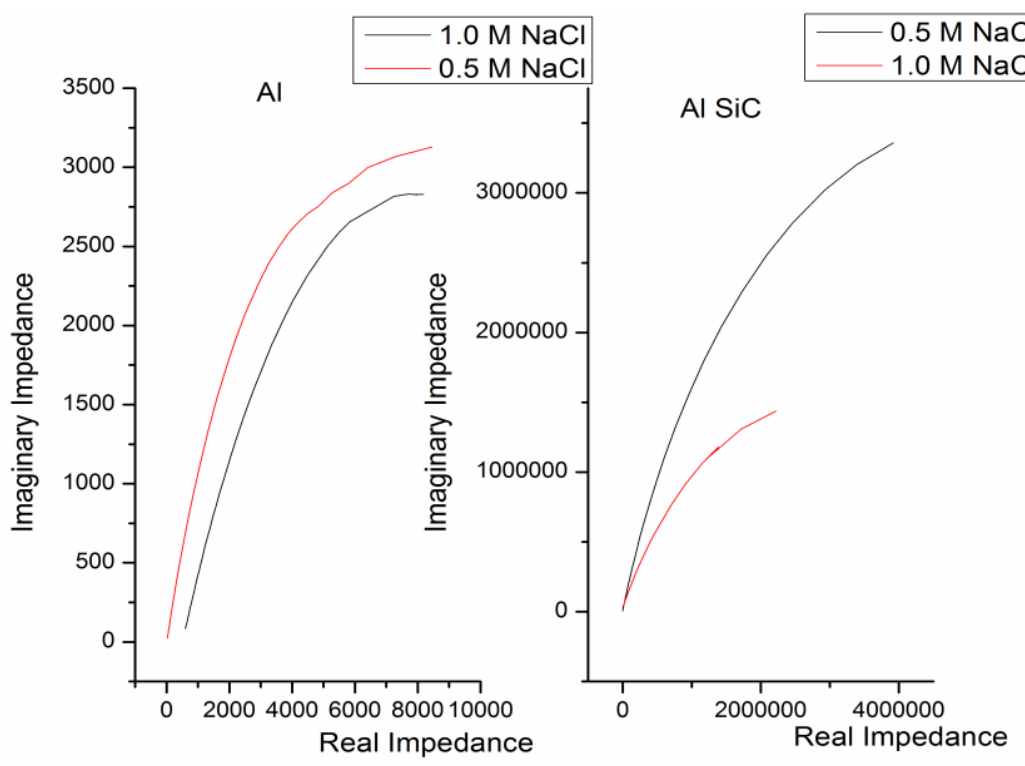




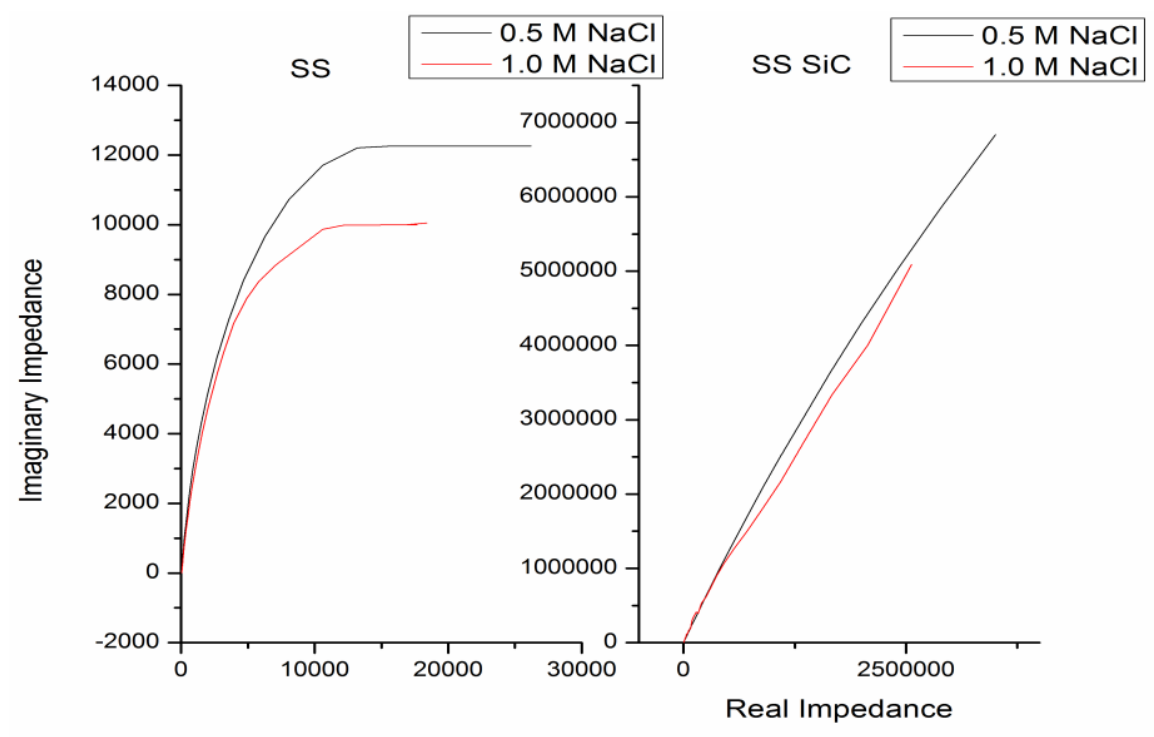

SS

Figure 2. Impedance diagram for SiC deposited on MS, Al and SS.

The quantitative data was given in Table 2, and it found that the polarization resistance $\mathrm{R}_{\mathrm{p}}$ coated metals indicates higher value compared to uncoated metals even the metal was exposed to the different temperature especially to mild steel coated with $\mathrm{SiC}$ that indicate higher resistance compared to mild steel without coating SiC.

Table 2. EIS data by different concentration of $\mathrm{NaCl}$ solution.

\begin{tabular}{lccc}
\hline $\begin{array}{c}\text { Type of } \\
\text { Metals }\end{array}$ & $\begin{array}{c}\text { Concentartaion of } \\
\text { Nacl solution }(\mathrm{M})\end{array}$ & $\begin{array}{c}\text { Polarization resistance } \\
\text { of uncoated, } \mathrm{R}_{\mathrm{p}}(\mathrm{K} \Omega)\end{array}$ & $\begin{array}{c}\text { Polarization resistance } \\
\text { of coated, } \mathrm{R}_{\mathrm{p}}(\mathrm{K} \Omega)\end{array}$ \\
\hline Mild steel & 0.5 & 3.643 & 45.11 \\
& 1.0 & 2.923 & 38.48 \\
Aluminium & 0.5 & 14.49 & 10.5 \\
& 1.0 & 10.527 & 5.68 \\
Stainless & 0.5 & 28.9 & 71.9 \\
steel & 1.0 & 23.656 & 68.4 \\
\hline
\end{tabular}

\section{Effect on Temperature}

The impedance diminution reveals the decrease of solution resistance, Rs, followed by polarization resistance, $\mathrm{R}_{\mathrm{p}}$. Reduction of polarization resistance indicates the increase of corrosion current and corrosion rate. Analytical results indicate that polarization resistance, $\mathrm{R}_{\mathrm{p}}$, decreases with increasing temperature. Diminution of polarization resistance represents the increase of corrosion current density, as well as corrosion rate. This phenomenon is in good agreement with Arrhenius' theory which said that any chemical reaction rate will increase with increasing temperature [43]. Temperature also affects the open-circuit potential, or in this case, corrosion resistance. Figure 3. (i), (ii) and (iii) respectively displays the influence of temperature toward corrosion resistance of different metal in $30^{\circ} \mathrm{C}$ and $50^{\circ} \mathrm{C}$ of temperature. This figure reveals that the metals that coated with silicon carbide nanocomposite exhibited larger diameters than the metals with uncoated even through the metals were exposed to the higher temperature at 
the metal surface. Corrosion resistance rises asymptotically with different temperature and only slightly increases with temperature augmentation. The better corrosion resistances of these coated metals were evident.

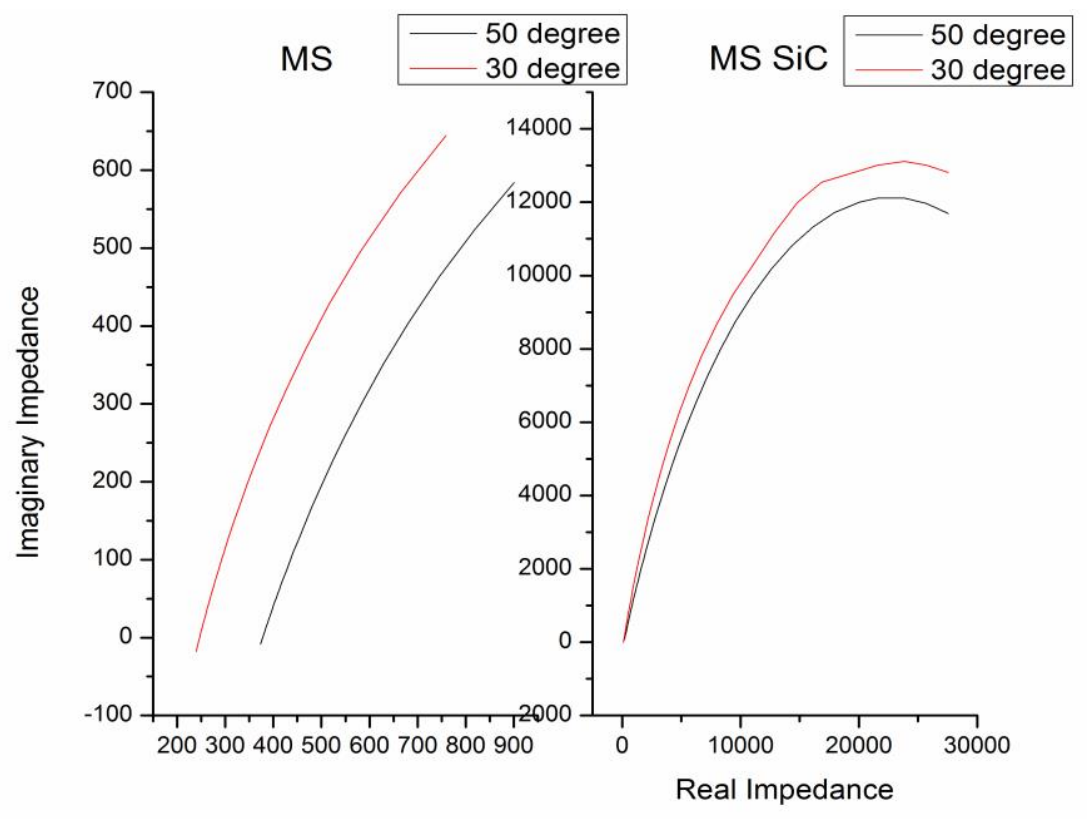

MS

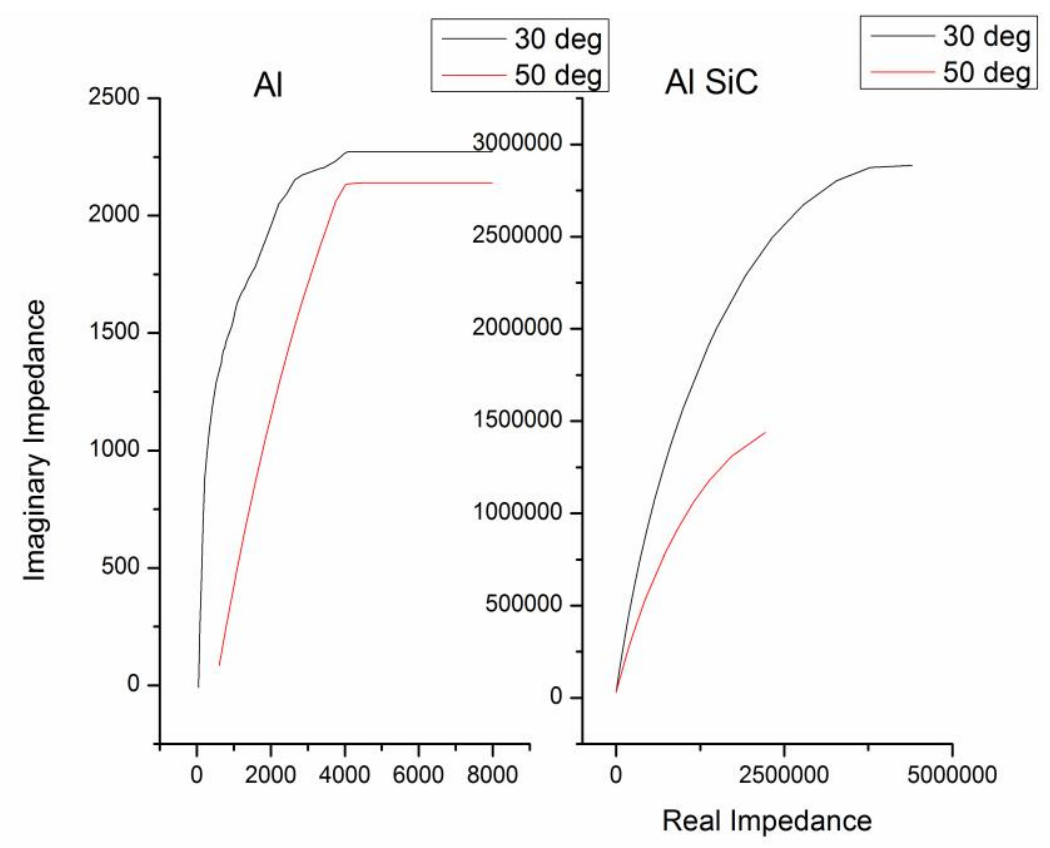




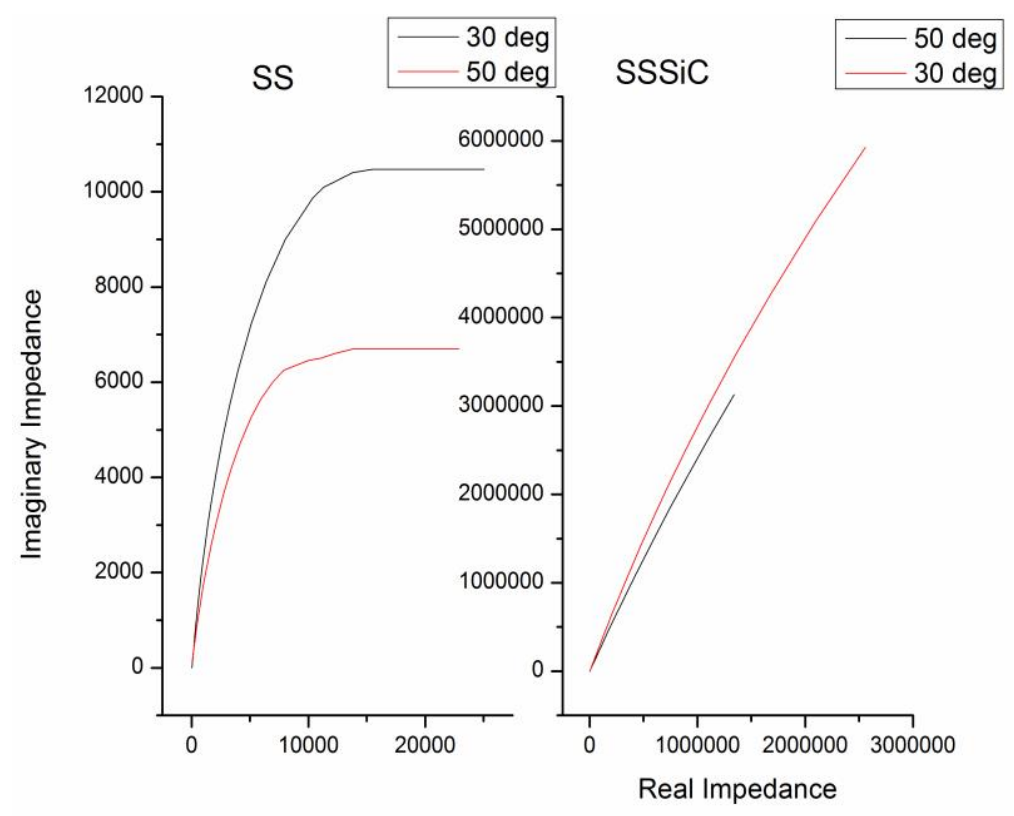

SS

Figure 3. Impedance diagram for SiC deposited on MS, Al and SS.

Table 3. EIS data by different temperature of electrolyte

\begin{tabular}{lccc}
\hline $\begin{array}{c}\text { Type of } \\
\text { Metals }\end{array}$ & $\begin{array}{c}\text { Concentartaion of } \\
\text { Nacl solution }(\mathrm{M})\end{array}$ & $\begin{array}{c}\text { Polarization resistance } \\
\text { of uncoated, } \mathrm{R}_{\mathrm{p}}(\mathrm{K} \Omega)\end{array}$ & $\begin{array}{c}\text { Polarization resistance } \\
\text { of coated, } \mathrm{R}_{\mathrm{p}}(\mathrm{K} \Omega)\end{array}$ \\
\hline Mild steel & 30 & 2.887 & 43.112 \\
& 50 & 2.754 & 38.962 \\
Aluminium & 30 & 18.345 & 8.35 \\
& 50 & 14.494 & 5.68 \\
Stainless & 30 & 28.732 & 61.9 \\
steel & 50 & 20.584 & 55.3 \\
\hline
\end{tabular}

\section{X-ray Diffraction (X-RD)}

The characteristics of intensity against 2 theta of the sample can be determined from the peak of 2theta whether crystalline or amorphous. To determine the crystalline pattern, there are peaks was shown in the graph of intensity against 2theta. Crystalline has a crystal and the molecules were line up in very particular order. While, amorphous is molecules are not in particular arrangement and has no crystal.

In the Figure 4. (ii), the XRD pattern of $\mathrm{SiC}$ coated on Aluminium give four peaks at $38.23^{\circ}, 44.47^{\circ}, 64.72^{\circ}$ and $77.75^{\circ}$. The peaks are represented of Al. There are no higher peaks of $\mathrm{SiC}$ were obtained and $\mathrm{SiC}$ were essentially amorphous. The XRD pattern of $\mathrm{SiC}$ coated on stainless steel give a peak at $45^{\circ}$ was shown in Figure 4. (iii). the peak was represented of Fe. There are no higher peaks of $\mathrm{SiC}$ were obtained and $\mathrm{SiC}$ were confirmed amorphous. 


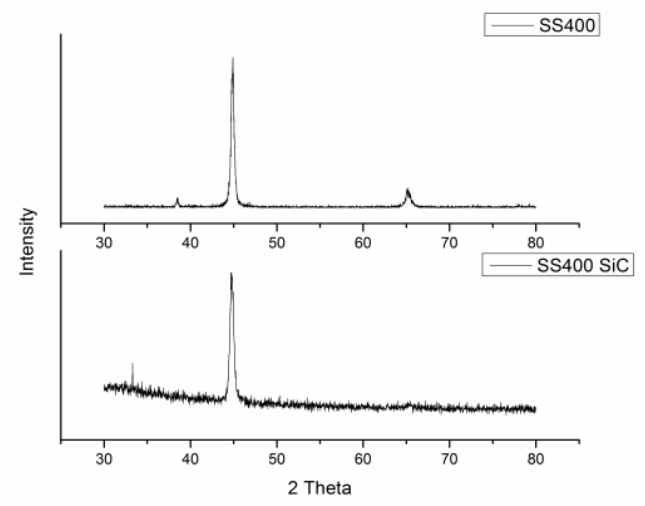

MS

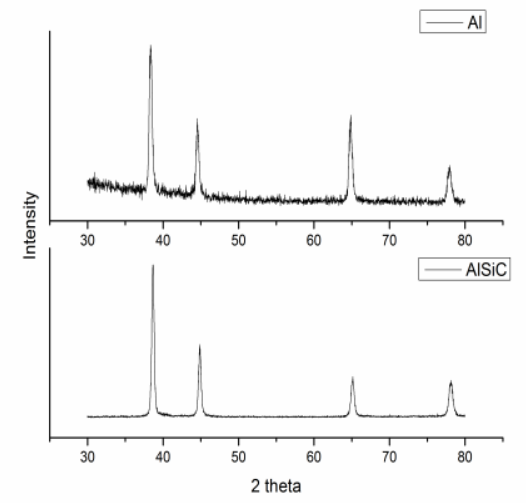

$\mathrm{Al}$

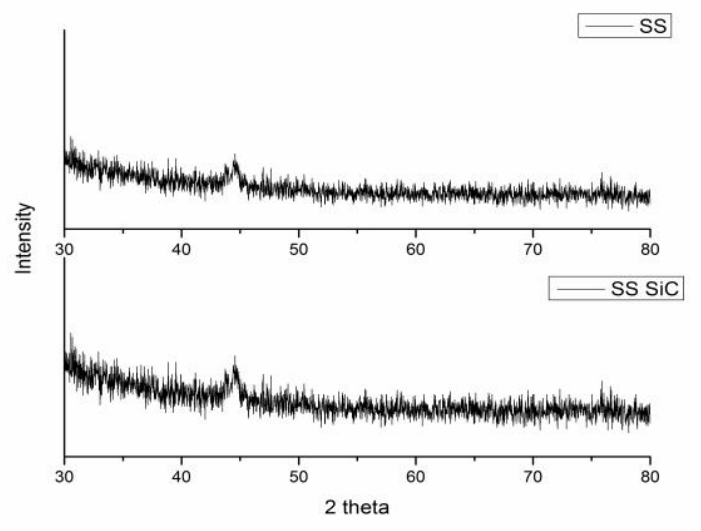

SS

Figure 4. Intensity against two-theta of MS, Al and SS

\section{CONCLUSIONS}

The investigation of prevention corrosion on different metal by using silicon carbide nanocomposite by magnetron sputtering is a relevant idea since the problem of corrosion become worse from day to day. Since the worldwide application of different metals in marine environment, people need to find out an appropriate method to reduce the corrosion rate in order to keep away from waste of money, source of metals and maintain efficient of machineries. An advantage of using magnetron sputtering process due to its significantly low cost, high deposition rates, low deposition temperature and resulting a good adhesion between coating and metal surface. The present study shows the goal for this experiment had been achieved through corrosion measurement. The weight loss measurement, it shows that uncoated metals loss more weight than coated metals for longer time of immersion. While based on corrosion rate results, the rate of corrosion coated metal was decrease obviously compared to the uncoated metals. The adsorbed inhibitor molecules are assumed to retard corrosion by reducing the number of available surface sites for corrosion and also slowing the rate of the corrosion reactions. Besides that, the higher value of Polarization Resistance $\left(R_{p}\right)$ from electrochemical impedance spectroscopy (EIS) shown that the metals coated with silicon carbide nanocomposite coating by magnetron sputtering increase obviously compared to the uncoated metals. Meanwhile, from X-ray diffraction (XRD) diagram, the phase of SiC was confirmed as amorphous. 


\section{ACKNOWLEDGEMENTS}

This study was funded by Research Acculturation Grant Scheme (RAGS 57109). The authors would like to thank all staffs and supporting members of Universiti Malaysia Terengganu (UMT) in conducting, finishing and completing this research study.

\section{REFERENCES}

[1] H Moller, ET Boshoff, H Froneman. The corrosion behavior of a low carbon steel in natural and synthetic seawater. The Journal of The South African Institute of Mining and Metallurgy, 2006; 6: 585-592.

[2] D Burleigh, VP Vavilov, SS Pawar. The influence of optical properties of paints and coatings on the efficiency of infrared nondestructive testing applied to Aluminium aircraft structures. Infrared Physics and Technology. 2016; 77: 230238.

[3] $M$ Chen, $S$ Zhu, $F$ Wang. High temperature oxidation of NiCrAIY, monocrystalline and enamel-metal nano-composite coatings under thermal shock. Corrosion Science; 2015; 100: 556-565, 2015.

[4] V Kumar, B Kandasubramanian. Processing and design methodologies for advanced and novel thermal barrier coatings for engineering applications. Particuology. 2016; 27: 1-28.

[5] S Syed. Atmospheric corrosion of materials, a review. Emirates Journal for Engineering Research. 2006; 11, No. 1:1-24.

[6] A Michel, PV Nygaard. MR Geiker. Experimental investigation on the shortterm impact of temperature and moisture on reinforcement corrosion. Corrosion Science. 2013; 72:26-34.

[7] A Safadoost, M Davoodi, SAA Mansoori. Preventing corrosion and tube failure in sulfur condenser during normal operation, startup, and shutdown of the south pars gas processing plant (case study). Journal of Natural Gas Science and Engineering. 2014;19: 105-115.

[8] Z Xingyu, L Ying, W Qingfeng, W Yuming. Frictional performance of silicon carbide under different lubrication conditions. Friction. 2014; 2(1): 58-63.

[9] M Das, V Krishna Balla, D Basu, S Bose, A Bandyopadhyay. Laser processing of SiC-particle-reinforced coating on titanium. Scripta Materialia. 2010; 63: 438-441.

[10] M Das, S Bysakh, D Basu, TS Sampath Kumar, V Krishna Balla, S. Bose, A. Bandyopadhyay. Microstructure, mechanical and wear properties of laser processed $\mathrm{SiC}$ particle reinforced coatings on titanium. Surface \& Coatings Technology. 2011;.205: 4366-4373.

[11] A Ordine, CA Achete, OR Mattos, ICP Margarit, SS Camargo Jr, T Hirsch. Magnetron sputtered SiC coatings as corrosion protection barriers for steels. Surface and Coatings Technology. 2000;133-134: 583-588.

[12] V Krishna Balla, A Bhata, S Bosea, A Bandyopadhyay, Laser processed TiN reinforced Ti6Al4V composite coatings. Journal of the Mechanical Behaviour of Biomedical Materials. 2012;.6: 9-20.

[13] J Prakash, D Sathiyamoorthy. Organometallic route to the chemical vacum deposition of silicon carbide film. IJMES. 2013; 6(1): 19-34.

[14] C Sella. JC Martin, J Lecoeur, A Le Chanu, MF Harmand, A Naji, JP Davidas, 
Biocomposite and corrosion resistance in biological media of hard ceramic coatings sputter deposited on metal implants, Materials Science and Engineering. 1991:139: 46-57.

[15] Dong-Joo Kim, Doo Jin Choi. High-temperature corrosion resistance of chemically vapor deposited silicon carbide against hydrogen chloride and hydrogen gaseous environment, Journal of the American Ceramic Society.2005; 79(2): $503-506$.

[16] MC Nestler, A Sharma, HM Hohle. Thermal spray materials and coatings for sustainable energy resources. Journal of Advanced Materials and Processing. 2013;117: 55-56.

[17] PJ Kelly, RD Arnell. Magnetron sputtering: a review of recent developments and applications. Vacuum. 2012; 56: 159-172.

[18] T Kim, D Singh, M Singh. Enhancement of oxidation resistance of graphite foams by polymer derived-silicon carbide coatings for concentrated solar power applications. Energy Procedia. 2015; 69 : 900-906.

[19] P Lu, P Ohlckers, L Muller, S Leopold, M Hoffmann, K Grigoras, J Ahopelto, M Prunnila, X Chen. Nano fabricated silicon nanorod array with titanium nitride coating for on-chip supercapacitors. Electrochemistry Communications. 2016;70: 51-55.

[20] JP Reviere, J Delafond, P Misaelides, F Noli, Corrosion protection of an AISI 321 stainless steel by $\mathrm{SiC}$ coatings. Surface and Coatings Technology.1998; 100-101:243-246.

[21] Wu M, Tian X, Li M, Gong C, Wei R, Effect of additional sample bias in Meshed Plasma Immersion Ion Deposition (MPIID) on microstructural, surface and mechanical properties of Si-DLC films. Applied Surface Science.2016; 376:26-33.

[22] Weber A, Remfort R., Woehrl N., Assenmacher W, Schulz S, Chemical vapor deposition of Si/SiC nano-multilayer thin films. Thin Solid Films. 2015; 593: 44-52.

[23] Raju K, Yu HW, Park JY, Yoon D H, Fabrication of $\mathrm{SiC}_{\mathrm{f}} / \mathrm{SiC}$ composites by alternating current electrophoretic deposition (AC-EPD) and hot pressing. Journal of the European Ceramic Society.2015;35(2):503-511.

[24] Genovese M, Lian K. Polyoxometalate modified inorganic-organic nanocomposite materials for energy storage application; a review. Current Opinion in Solid State Materials Science.2015; 19(2):126-137.

[25] Y Du, SZ Shen, K Cai, PS Casey.Research progress on polymer-inorganic thermoelectric nanocomposite materials. Progress in Polymer Science.2012; 37(6):820-841.

[26] M Kormunda, J Pavlik, A Mackova, P Malinsky. Characterization of off-axis single target RF magnetron co-sputtered ion doped tin oxide films. Surface and Coatings Technology.2010: 205:120-124.

[27] M Aiempanakit, T Kubart, P Larsson, K Sarakinos, J Jensen, U Helmersson. Hysteresis and process stability in reactive high power impulse magnetron sputtering of metal oxides. Thin Solid Films.2011;519(22):7779-7784.

[28] TP Drusedau. Investigating of the throw distance of sputtered atoms under consideration of gas rarefaction. Surface and Coatings Technology.2003;174175: 470-474.

[29] R Sitriani, CE Corcione, GDA Muia and M Frigione. Durability of a sunlightcurable organic-inorganic hybrid protective coating for porous stones in natural 
and artificial weathering conditions. Progress in Organic Coatings. 2016; 101:114.

[30] AM Abdel-Gaber, BA Abd-El-Nabey, E Khamis, DE Abd-El-Khalek, Investigation of fig leaf extract as a novel environment friendly antiscalent for $\mathrm{CaCO}_{3}$ calcareous deposits. Desalination. 2008; 230(1-3):314-428.

[31] SE Ziemniak, M Hanson, Zinc treatment on corrosion behavior of Alloy 600 in high temperature hydrogenated water. Corrosion Science. 2013; 48(10):33303348.

[32] IL Lehr, SB Saidman, Anticorrosive properties of polypyrrole films modified with zinc onto SAE 4140 steel. Progress in Organic Coatings. 2013;76(11): 1586-1593.

[33] Y Tavan, H Gholami, S Shahhosseini. Some notes on process intensification of amine based gas sweetening process for better temperature distribution in contractor to reduce the amount of amine as a result of corrosion and foaming. Journal of Loss Prevention in the Process Industries. 2016;41:169-177.

[34] RA. Bajaresa, L Di Mellaa, Study of the corrosion rate in the couple of steels ASTM A-36 and AISI/SAE 304 in a water-coke of petroleum system, Procedia Materials Science.2015;8:702-711.

[35] ASTM E-112.Metal test methods and analytical procedures, in Annual Book of ASTM Standards. 03.01. Section 3. ASTM International. West Conshohocken, Pa USA. 2007.

[36] M Watanabe, Y Higashi, T Tanaka, Differences between corrosion products formed on copper exposed in Tokyo in summer and winter. Corrosion Science, 2003; 45(7):1439-1453.

[37] H Shin, J Park, AM Sastry, W Lu, Degradation of solid electrolyte interphase induced by the deposition of manganese ions. Journal of Power Sources. 2015;284:416-427.

[38] Z Feng, X Cheng, C Dong, L Xu, X Li, Passivity of 316L stainless steel in borate buffer solution studied by Mott-Schottky analysis, atomic absorption spectrometry and X-ray photoelectron spectroscopy, Corrosion Science, Vol. 52 (11), pp. 3646-3653, 2010.

[39] U. Trdan, J Grum. SEM/EDS characterization of laser shock peening effect on localized corrosion of $\mathrm{Al}$ alloy in a near natural chloride environment. Corrosion Science.2014;82:328-338.

[40] R Arrabal, A Pardo, M.C. Merino, M. Mohedano, P. Casajus, S. Merino. A1/SiC thermal spray coatings for corrosion protection of $\mathrm{Mg}-\mathrm{Al}$ alloys in humid and saline environments. Surface and Coatings Technology.2010;204(16-17):27672774.

[41] DA Shifler. Understanding material interactions in marine environments to promote extended structural life. Corrosion Science. 2005;47(10):2335-2352.

[42] C Liu, A Leyland, Q Bi, A Matthews. Corrosion resistance of multi-layered PAPVD TiN and CrN coatings. Surface Coating Technology. 2001;141:164-175.

[43] VHC Silva,V Aquilanti, HCB Oliveira, KC Mundim. Uniform description of non-Arrhenius temperature dependence of reaction rates, and a heuristic criterion for quantum tunneling vs. classical non-extensive distribution. Chemical Physics Letters.2013;590:201-207. 